\title{
Effect of Eight Weeks Aerobic and Combined Training on Serum Levels of Sirtuin 1 and PGC-1 $\alpha$ in Coronary Artery Bypass Graft Patients
}

\author{
Najmatol Sabah Alavizadeh (PhD) \\ Student of Sports Physiology, Islamic \\ Azad University of Neyshabour, \\ Neyshabour, Iran \\ Amir Rashidlamir (PhD) \\ Department of Sports Physiology, \\ Faculty of Sports Sciences, Ferdowsi \\ University of Mashhad, Mashhad, Iran \\ Seyed Mahmood Hejazi (PhD) \\ Department of Sports Physiology, \\ Faculty of Sports Sciences, Islamic \\ Azad University of Mashhad, \\ Mashhad, Iran \\ Corresponding author: Amir \\ Rashidlamir \\ Email: rashidlamir@um.ac.ir \\ Tel: +989151514174 \\ Address: Ferdowsi University of \\ Mashhad, Mashhad, Iran \\ Received : 28 Jan 2018 \\ Revised: 05 Jun 2018 \\ Accepted: 18 Jun 2018
}

\begin{abstract}
Background and objectives: Sirtuin-l (SIRTl) is a conserved a NAD+-dependent protein deacetylase essential for cellular metabolism and defence against oxidative stress and endothelial dysfunction. This study aimed to compare effects of 8 weeks of aerobic and combined training on serum level of SIRTI and PGCl- $\alpha$ in coronary artery bypass graft patients.

Methods: In this semi-experimental study, 45 non-active men (mean age $47.4 \pm 3.3$ years) who had undergone coronary artery bypass graft surgery were randomly divided into three groups: aerobic training, combined resistance and aerobic training and control. Trainings were performed at $\mathbf{8 0 \%}$ of maximum heart rate, three sessions a week for 8 weeks. Blood samples were collected 24 hours before the first exercise session and 48 hours after the last training session. T-test and one-way analysis of variance were used for assessment of within-group and between-group differences, respectively. P-values less than 0.05 were considered as statistically significant.

Results: The 8-week aerobic and combined training increased serum levels of SIRT1 and PGC-1 $\alpha$ compared with the control group, and significantly decreased the weight of subjects $(\mathrm{p}=0.001)$. There was no significant difference in serum levels of SIRT1 and PGC-l $\alpha$ between the two training groups $(\mathrm{P} \geq 0.05)$.

Conclusion: Both combined and aerobic training significantly improve the SIRT1 and PGC-l $\alpha$ levels in coronary artery bypass graft patients.

KEYWORIS: Combined training, Aerobic training, PGC-l $\alpha$, SIRT1, CABG patient.
\end{abstract}

This paper should be cited as: Alavizadeh N, Rashidlamir A, Hejazi SM [Effect of Eight Weeks Aerobic and Combined Training on Serum Levels of Sirtuin 1 and PGC-1a in Coronary Artery Bypass Graft Patients]. mljgoums. 2018; 12(5):50-56 


\section{INTRODUCTION}

Despite the recent advancements in diagnostic and clinical tools along with therapeutic methods, the incidence of heart failure is on the rise (1). Today, exercise-based cardiac rehabilitation program (CRP) has been introduced as the main component of the chain of care for heart failure patients. Studies have shown that CPR, significantly decreases the mortality rates due to heart failure. However, these studies have been rarely conducted on the elderly or high-risk patients who cannot easily participate in these exercises (2). Several studies demonstrate that exercise in heart failure patients is strongly correlated with cardiovascular and hemodynamic parameters (3). However, little information confirms the molecular mechanisms of exercise in the cardiac rehabilitation program. In both humans and animal models, exercise induces secretion of defense antioxidants and therefore reduces reactive oxygen species (4). Physical activity or muscle contraction not only consumes intracellular energy (calorie restriction) but also regulates the increase in the level of proteins involved in energy metabolism. The calorie restriction caused by exercise can decelerate the aging process and delay the onset of many age-related diseases such as Alzheimer's disease, diabetes, obesity and cardiovascular disease (CVD) (5). Consequently, exercise-induced calorie restriction can be an effective therapeutic approach for patients with CVD.

The family of sirtuin (SIRT) proteins has NAD-dependent protein acetylase and/or ADP-ribosyl transferase-dependent activity (6). These proteins regulate various biological processes including DNA repair, genome stability and fat and glucose homeostasis (7, 8). Studies have shown that these enzymes are key regulators of cell survival and lifespan of organisms (9). Seven SIRT proteins (SIRT 17) have been identified in mammals, which are located in different cell segments and have various functions (10).

SIRT 1, 6 and 7 are located inside the nucleus and the rest of these proteins are in the cytoplasm and mitochondria (11). SIRT proteins are classified based on their function; SIRT 1, 2, 3 and 5 have deacetylase activity (12) among which, SIRT1 has the highest deacetylase activity (13). SIRT1 is effective against oxidative stress and endothelial dysfunction, which are both associated with endothelial cell pathophysiology and CVD (14). Evidence on the protective role of SIRT1 in vascular biology suggests that this protein can be a major contributor to prevention of CVD and several other diseases (15). In fact, SIRT1 plays an important role in aging and cell damage, and stimulates antioxidant enzymes, such as superoxide dismutase and catalase (16). SIRT1 also regulates blood pressure, atherosclerosis, oxidative stress protection and growth and survival of cardiomyocytes (17). One of the main reasons for cell death is genotoxic stress due to NAD ${ }^{+}$ release into the nucleus and cytoplasm (18). As key activators of SIRT proteins, cellular level of $\mathrm{NAD}^{+}$plays a role in cell death and lifespan. $\mathrm{NAD}^{+}$is required for the deacetylase activity of SIRT1 and SIRT3, which elucidates the fundamental link between the activity of these proteins and the fluctuations in the $\mathrm{NAD}^{+}(\mathrm{H})$ state during exercise (19). Studies demonstrate that SIRT1 and 3 level is reduced in aging but increased in endurance-trained individuals (20). It has been shown that exercise and chronic electrical stimulation (21) but not acute exercise (21) increase the level of SIRT1 and 3 in the skeletal muscles. Lu et al. have recently shown that small amounts of SIRT1 in patients with severe heart failure inhibited antioxidants and caused oxidative stress and apoptosis (22). In another study, Ferrara et al. showed that moderate-intensity exercise in mice activates SIRT1 and increases superoxide dismutase and catalase levels (23). Peroxisome proliferator-activated receptor gamma coactivator 1-alpha (PGC-1 $\alpha$ ) is a cellular receptor that facilitates the release of mitochondrial proteins, and is one of the main regulators of mitochondrial biogenesis. On the other hand, the relationship between muscle oxidative capacity and cellular health has been well established through SIRT (24). Increased SIRT1 levels results in an increase in the activity of PGC- $1 \alpha$ and ultimately mitochondrial biogenesis in various cells, including skeletal muscle cells (25). Studies suggest that mitochondrial dysfunction might play a role in the development and progression of sarcopenia either through reduced energy storage or mitochondrial-mediated apoptosis (26). Studies have shown that increased aerobic capacity and muscle strength through exercise can improve metabolic disorders and prevent chronic illnesses (27). 
Adaptation to training can include changes in the structure and function of contractions (28), mitochondrial function (29), metabolic regulation (30), intracellular signaling (31) and transcriptional responses (32). In this regard, Martin et al. observed that high intensity interval training (four sessions of bicycle riding with maximum intensity and four minutes of rest) could activate various signaling pathways, resulting in increased mitochondrial biogenesis in human skeletal muscles and increased oxidation capacity of fatty acids and glucose. They observed that signaling via AMPK and P38 MAPK to PGC$1 \alpha$ may partly justify the changes caused by the intense, low-volume periodic exercise (33). Despite the important physiological role of SIRT1, the impact of exercise on the level of this protein in CVD patients is unclear. Exercise affects regulatory proteins involved in glucose control and mitochondrial biogenesis, which may be beneficial for people with low mobility. Therefore, we studied the effect of aerobic and combined training on serum level of SIRT1 and PGC1- $\alpha$ in men undergoing coronary artery bypass graft (CABG) surgery.

\section{MATERIAL AND METHODS}

This was a semi-experimental study with a pre- and post-test design. Study population included 45 men (aged 40-60 years) who had undergone open heart surgery at the Javad-ol-Aeme Mashhad clinic. The subjects volunteered to participate in the study and were selected based on available sampling method. The inclusion criteria were: age range of 40-60 years, willingness to participate in the study, cognitive health, adequate vision and hearing and the inability to use auxiliary devices for walking such as a cane and walker, and no exercise or sports activity during the research. Exclusion criteria included systolic blood pressure greater than $160 \mathrm{mmHg}$ and diastolic blood pressure greater than 100 $\mathrm{mmHg}$, acute or advanced disease that prevents the exercises intended in this study, use of anticonvulsant medications, and occurrence of ventricular arrhythmias and ST elevation or fall in ECG during training, respiratory disturbance during rehab and unstable angina. After completing the informed consent form, the subjects were randomly divided into three groups of aerobic training $(\mathrm{n}=15)$, combined training $(\mathrm{n}=15)$ and control $(\mathrm{n}=15)$. The subjects in the aerobic and combined training groups participated in an 8week training program based on the recommendation of the American College of Sports Medicine $(34,35)$. The control group was asked to maintain their normal daily activities during the study period. The study received approval from the ethics committee of Islamic Azad University of Neyshabour, Iran (approval code: IR.IAU.NEYSHABUR.1396,13).

One week before the start of the study, the subjects participated in an introductory session and were familiarized with the correct way of training. The rehabilitation program was performed for eight weeks (3 sessions per week) and each session lasted 30-60 minutes based on assessments (cardiopulmonary exercise test, exercise testing, etc.). The aerobic training consisted of walking on a treadmill for 20-30 minutes and cycling on a stationary bike (10-12 minutes). In each training session, the subjects warmed up at the beginning of training and cooled down after the main training protocol. Exercises began at moderate intensity. In this regard, $60 \%$ of the maximum heart rate was considered as the target heart rate, and the duration and intensity of the exercises were adjusted accordingly (36). The duration and intensity of the training was gradually increased based on the subjects' ability, so that in the final session the trainings were performed at $80 \%$ of maximum heart rate. The Borg 6-20 scale was used to assess the exercise intensity $(37,38)$. The specified trainings were performed for 8 weeks, 3 sessions per week, with 8 repetitions and 3 sets in the initial training sessions (later increased to 15 repetitions). The exercises included physioball squat, shoulder flexion, hip flexion, shoulder abduction, hip abduction, elbow flexion, plantar flexion and ankle dorsiflexion. The activities were initially performed with 8 repetitions using a weak Thera-Band (yellow). Two repetitions were added in each training session and the number of repeats. Then, the strength of the Thera-Band (pink) was increased in subsequent sessions (35). All trainings were performed under the supervision of a physician and a CCU nurse, and the patients received psychological and nutrition counseling during the training period. It should be noted that all patients were studied under the same conditions and were taking beta-blockers and angiotensin-antagonists 
under the supervision of a physician. Fasting blood samples $(10 \mathrm{cc})$ were taken from the cubital vein a day before the first training session and 48 hours after the last training session. The specimens were incubated for 20 minutes at room temperature and then were centrifuged at 3000 RPM for 20 minutes. Serum was separated and stored at $-80{ }^{\circ} \mathrm{C}$ until testing. Serum levels of SIRT1 and PGC- $1 \alpha$ were measured using an ELISA reader and Cusabio ELISA kits (China) with a sensitivity of less than $0.39 \mathrm{ng} / \mathrm{ml}$ (0.039 sensitivity). After verifying the normal distribution of data via the Shapiro Wilk test, t-test was used to analyze intra-group variations and one-way ANOVA and Tukey's post hoc test were used for analysis of inter-group variations. Data are presented as mean \pm standard deviation (SD). All statistical analyses were performed using SPSS version 21 at significance level of $\leq 0.05$.

\section{RESULTS}

characteristics of the subjects are presented in table 1. Serum levels of SIRT1 and PGC-1 $\alpha$ increased significantly in both experimental groups $(\mathrm{P} \leq 0.01)$, but there was no significant difference between the two experimental groups (Table 2). Results of the Tukey's test indicated a significant difference between both experimental groups and the control group in terms of SIRT and PGC1- $\alpha$ level

Table 1- Biometrics and some characteristics of the subjects

\begin{tabular}{|c|c|c|c|c|c|c|}
\hline Group & $\mathbf{N}$ & Age (years) & Height (m) & Weight (Kg) & $\begin{array}{c}\text { Weight after } \\
\text { implementing } \\
\text { protocol }\end{array}$ & $\begin{array}{c}\text { Duration of disease } \\
\text { (months) }\end{array}$ \\
\hline Aerobic training & 15 & $46.9 \pm 3.23$ & $171.1 \pm 3.6$ & $80.14 \pm 9.12$ & $80.1 \pm 9.3$ & $150 \pm 68.19$ \\
\hline Combined training & 15 & $47.4 \pm 3.23$ & $170.2 \pm 3.5$ & $80.16 \pm 8.99$ & $79.03 \pm 8.95$ & $150 \pm 69.01$ \\
\hline Control & 15 & $47.4 \pm 2.75$ & $170.9 \pm 3.9$ & $80.01 \pm 8.8$ & $79.2 \pm 9.21$ & $149 \pm 69.12$ \\
\hline
\end{tabular}

Table 2- Comparison of SIRT1 and PGC-1 $\alpha$ levels between the study groups using one-way ANOVA and Tukey's test

\begin{tabular}{ccc}
\hline Variable & Groups & Sig \\
\hline $\begin{array}{c}\text { SIRT1 } \\
(\text { ng/ml })\end{array}$ & Aerobic-Control & 0.001 \\
& Combined- Control & 0.001 \\
& Aerobic-Combined & 0.91 \\
PGC-1 $\alpha$ & Aerobic- Control & 0.001 \\
$(\mathbf{p g} / \mathbf{m l})$ & Combined- Control & 0.001 \\
& Aerobic- Combined & 0.066 \\
\hline
\end{tabular}

\section{DISCUSSION}

The main finding of the present study was the elevation of SIRT1 and PGC- $1 \alpha$ levels in CABG patients after 8 weeks of aerobic and combined training. However, there was no significant difference between aerobic training and combined training. Some studies suggested exercise as a promising therapeutic approach that can increase the aerobic capacity of heart failure patients. Russomanno et al. conducted a study on endothelial cells of patients before and after a CPR and concluded that the training program could stimulate SIRT1 and antioxidant defense, which is accomplished by mitochondrial biogenesis. In a study by Ma et al. (2013), a 4-week highintensity interval training program with $170 \%$ of aerobic power peak on the ergometer had no effect on the SIRT1 level (39). Marton et al. (2015) showed that 3 months of swimming with $70 \%$ of $\mathrm{VO}_{2} \max$ in healthy rats does not affect serum level of SIRT, but improves the metabolic status of subjects (40). This contradiction between the results of studies may be due to differences in the method of implementation, age and readiness of subjects, gender, disease status and the physical composition of the subjects. Cellular aging is one of the signs of aging and a process that permanently prevents the growth of potentially powerful cells. The relationship between age, disability and age-related diseases remains as one of the major questions in the aging 
physiology and clinical and preclinical medicine. Aging caused by oxidative stress can damage endothelial cells, resulting in impairment of the structure and function of endothelial cells. Some researchers believe that cellular aging is associated with endothelial dysfunction and atherogenesis. Histological studies on human atherosclerotic plaques have shown morphological features of aging. Oxidative stress-induced endothelial dysfunction has been shown to be highly dependent on heart failure and endothelial homeostasis and cellular aging with SIRT1 (41). The increased level of SIRT1 following aerobic and combined exercise can affect the endothelial cells of the cardiac muscle. Various protein factors have been demonstrated to be involved in mitochondrial function, the most important of which are PGC-1 $\alpha$ and SIRT1. SIRT1 reduces the mitochondrial membrane potential and generates reactive oxygen species while increasing cell respiration (42). Physical activity activates PGC- $1 \alpha$ in the muscle fibers through nitric oxide (NO), P38 AMPK, kinasedependent calcium, cAMP-dependent AMPK and overexpression of nuclear respiratory factors (43). The enzymatic activity of SIRT requires $\mathrm{NAD}^{+}$as a cofactor, and the amount of serotonin significantly increases following energy stress, such as caloric restriction due to exercise and hunger (36). This has been observed in a number of studies, and the increase in $\mathrm{NAD}^{+}$potentially increases the activity of SIRT (44). Therefore, elevated SIRT1 following exercise is mainly caused by energy stress and adaptation to training accompanied by increased mitochondrial density, resulting in increased $\mathrm{NAD}^{+} / \mathrm{NADH}$ content. Little et al. reported that two weeks

\footnotetext{
References

1. Mozaffarian D, Benjamin EJ, Go AS, Arnett DK, Blaha MJ, Cushman M, et al. Heart disease and stroke statistics-2015 update: a report from the American Heart Association. Circulation. 2015;131(4):e29-e322. https://doi.org/10.1161/CIR.0000000000000152.

2. Schutzer KA, Graves BS. Barriers and motivations to exercise in older adults. Preventive medicine. 2004; 39(5): 1056-61. https://doi.org/10.1016/j.ypmed.2004.04.003

3. Ismail H, McFarlane JR, Nojoumian AH, Dieberg G, Smart NA. Clinical outcomes and cardiovascular responses to different exercise training intensities in patients with heart failure: a systematic review and meta-analysis. JACC Heart Failure. 2013; 1(6): 514-22. https://doi.org/10.1016/j.jchf.2013.08.006.
}

of high-intensity interval training notably increased SIRT1 levels and triggered overexpression of oxidative enzymes, ultimately reducing oxidative stress and enhancing training performance (45). Narou et al. studied the effect of 8 weeks of running on treadmill (for 50 minutes, 5 days a week) on level of SIRT1, PGC-1 $\alpha$ and AMPK in quadriceps muscles of middle-aged rats(46). Cassault et al. showed that the level of SIRT1 and mitochondrial biogenesis in healthy exercised rats increased after 6 weeks of quercetin supplementation and/or exercise training (47). They believed that cAMPdependent protein kinase and nicotinamide phosphoribosyltransferase increase the intracellular level of $\mathrm{NAD}^{+}$during muscle contractions, which is associated with SIRT elevation (48). It should be mentioned that our study was limited to male CABG patients and did not include $C A B G$ patients not receiving cardiac rehabilitation. Therefore, it is recommended to conduct future studies without these limitations to obtain more accurate information on the effect of the trainings on serum levels of SIRT1 and PGC1$\alpha$ in coronary artery bypass graft patients.

\section{CONCLUSION}

Both combined and aerobic training significantly improve the SIRT1 and PGC-1 $\alpha$ levels in coronary artery bypass graft patients.

\section{ACKNOWLEDGEMENTS}

We would like to express our gratitude to Dr. Alavi for the helpful comments.

\section{CONFLICT OF INTEREST}

The authors declare that they have no conflict of interest.

4. Meyer P, Gayda M, Juneau M, Nigam A. Highintensity aerobic interval exercise in chronic heart failure. Current heart failure reports. 2013; 10(2): 130-8. https://doi.org/10.1007/s11897-013-0130-3.

5. Gan L. Therapeutic potential of sirtuin-activating compounds in Alzheimer's disease. Drug News Perspect. 2007; 20(4): 233-9. https://doi.org/10.1358/dnp.2007.20.4.1101162.

6. Palacios OM, Carmona JJ, Michan S, Chen KY, Manabe Y, Ward Iii JL, et al. Diet and exercise signals regulate SIRT3 and activate AMPK and PGC-1 $\alpha$ in skeletal muscle. Aging (Albany NY). 2009;1(9):771-83. https://doi.org/10.18632/aging.100075. 
7. Haigis MC, Guarente LP. Mammalian sirtuinsemerging roles in physiology, aging, and calorie restriction. Genes \& development. 2006; 20(21): 291321. https://doi.org/10.1101/gad.1467506

8. Michan S, Sinclair D. Sirtuins in mammals: insights into their biological function. Biochemical Journal. 2007; 404(1): 1-13. https://doi.org/10.1042/BJ20070140.

9. Guarente L, Picard F. Calorie restriction-the SIR2 connection. Cell. 2005; 120(4): 473-82.

https://doi.org/10.1016/j.cell.2005.01.029.

10. Michishita E, Park JY, Burneskis JM, Barrett JC, Horikawa I. Evolutionarily conserved and nonconserved cellular localizations and functions of human SIRT proteins. Molecular biology of the cell. 2005; 16(10): 4623-35. https://doi.org/10.1091/mbc.e05-01-0033.

11. Cooper HM, Spelbrink JN. The human SIRT3 protein deacetylase is exclusively mitochondrial. Biochemical Journal. 2008; 279-85. https://doi.org/10.1042/BJ20071624.

12. Potente M, Dimmeler S. Emerging roles of SIRT1 in vascular endothelial homeostasis. Cell cycle. 2008; 7(14): 2117-22. https://doi.org/10.4161/cc.7.14.6267.

13. Satoh A, Stein L, Imai S. The role of mammalian sirtuins in the regulation of metabolism, aging, and longevity. Histone Deacetylases: the Biology and Clinical Implication: Springer. 2011; 125-62.

14. Tanno M, Kuno A, Horio Y, Miura T. Emerging beneficial roles of sirtuins in heart failure. Basic research in cardiology. 2012; 107(4): 273. https://doi.org/10.1007/s00395-012-0273-5.

15. Corbi G, Conti V, Russomanno G, Longobardi G, Furgi G, Filippelli A, et al. Adrenergic signaling and oxidative stress: a role for sirtuins? Front physiol. 2013; 4: 324. https://doi.org/10.3389/fphys.2013.00324.

16. Conti V, Corbi G, Simeon V, Russomanno G, Manzo $\mathrm{V}$, Ferrara N, et al. Aging-related changes in oxidative stress response of human endothelial cells. Aging clinical and experimental research. 2015; 27(4): 547-53. https://doi.org/10.1007/s40520-015-0357-9.

17. Cui Y, Wang H, Chen H, Pang S, Wang L, Liu D, et al. Genetic analysis of the SIRT1 gene promoter in myocardial infarction. Biochemical and biophysical research communications. 2012; 426(2): 232-6. https://doi.org/10.1016/j.bbrc.2012.08.071.

18. Yang H, Yang T, Baur JA, Perez E, Matsui T, Carmona JJ, et al. Nutrient-sensitive mitochondrial NAD+ levels dictate cell survival. Cell. 2007; 130(6): 1095-107. https://doi.org/10.1016/j.cell.2007.07.035.

19. White AT, Schenk S. NAD+/NADH and skeletal muscle mitochondrial adaptations to exercise. American Journal of Physiology-Endocrinology and Metabolism. 2012; 303(3): $\quad$ E308E21.https://doi.org/10.1152/ajpendo.00054.2012.

20. Lanza IR, Short DK, Short KR, Raghavakaimal S, Basu R, Joyner MJ, et al. Endurance exercise as a countermeasure for aging. Diabetes. 2008; 57(11): 293342. https://doi.org/10.2337/db08-0349.

21. Gurd BJ, Holloway GP, Yoshida Y, Bonen A. In mammalian muscle, SIRT3 is present in mitochondria and not in the nucleus; and SIRT3 is upregulated by chronic muscle contraction in an adenosine monophosphate-activated protein kinase-independent manner. Metabolism. 2012; 61(5): 733-41. https://doi.org/10.1016/j.metabol.2011.09.016.
22. Lu T-M, Tsai J-Y, Chen Y-C, Huang C-Y, Hsu H-L, Weng C-F, et al. Downregulation of Sirtl as aging change in advanced heart failure. Journal of biomedical science. 2014; 21(1): 57. https://doi.org/10.1186/14230127-21-57.

23. Ferrara N, Rinaldi B, Corbi G, Conti V, Stiuso P, Boccuti $\mathrm{S}$, et al. Exercise training promotes SIRT1 activity in aged rats. Rejuvenation research. 2008; 11(1): 139-50. https://doi.org/10.1089/rej.2007.0576.

24. Coffey VG, Hawley JA. The molecular bases of training adaptation. Sports medicine. 2007; 37(9): 73763. https://doi.org/10.2165/00007256-200737090-00001.

25. Hokari F, Kawasaki E, Sakai A, Koshinaka K, Sakuma K, Kawanaka K. Muscle contractile activity regulates Sirt3 protein expression in rat skeletal muscles. Journal of applied physiology. 2010; 109(2): 332-40. https://doi.org/10.1152/japplphysiol.00335.2009.

26. Bua EA, McKiernan SH, Wanagat J, McKenzie D, Aiken JM. Mitochondrial abnormalities are more frequent in muscles undergoing sarcopenia. Journal of applied physiology. 2002; 92(6): 2617-24. https://doi.org/10.1152/japplphysiol.01102.2001.

27. Egan B, Zierath JR. Exercise metabolism and the molecular regulation of skeletal muscle adaptation. Cell metabolism. 2013; 17(2): 162-84. https://doi.org/10.1016/j.cmet.2012.12.012.

28. Widrick JJ, Stelzer JE, Shoepe TC, Garner DP. Functional properties of human muscle fibers after shortterm resistance exercise training. American Journal of Physiology-Regulatory, Integrative and Comparative $\begin{array}{lll}\text { Physiology. 2002; } 283(2): & \text { R408-R16. }\end{array}$ https://doi.org/10.1152/ajpregu.00120.2002.

29. Spina RJ, Chi M, Hopkins MG, Nemeth P, Lowry O, Holloszy J. Mitochondrial enzymes increase in muscle in response to 7-10 days of cycle exercise. Journal of applied physiology. 1996; 80(6): 2250-4. https://doi.org/10.1152/jappl.1996.80.6.2250.

30. Green H, Helyar R, Ball-Burnett M, Kowalchuk N, Symon S, Farrance B. Metabolic adaptations to training precede changes in muscle mitochondrial capacity. Journal of Applied Physiology. 1992; 72(2): 484-91. https://doi.org/10.1152/jappl.1992.72.2.484.

31. Benziane B, Burton TJ, Scanlan B, Galuska D, Canny BJ, Chibalin AV, et al. Divergent cell signaling after short-term intensified endurance training in human skeletal muscle. American Journal of PhysiologyEndocrinology and Metabolism. 2008; 295(6): E1427E38. https://doi.org/10.1152/ajpendo.90428.2008.

32. Pilegaard H, Saltin B, Neufer PD. Exercise induces transient transcriptional activation of the PGC-1 $\alpha$ gene in human skeletal muscle. The Journal of physiology. 2003; 546(3): 851-8. https://doi.org/10.1113/jphysiol.2002.034850.

33. Gibala MJ, McGee SL, Garnham AP, Howlett KF, Snow RJ, Hargreaves M. Brief intense interval exercise activates AMPK and 338 MAPK signaling and increases the expression of PGC-1 $\alpha$ in human skeletal muscle. Journal of applied physiology. 2009; 106(3): 929-34. https://doi.org/10.1152/japplphysiol.90880.2008.

34. Thompson W, Gordon N, Pescatello L. American College of Sport Medicine. ACSM's Guidelines for exercise testing and prescription. 8. painos. Philadelphia. Lippincott Williams and Wilkins; 2009. 
35. Pollock ML, Franklin BA, Balady GJ, Chaitman BL, Fleg JL, Fletcher $\mathrm{B}$, et al. Resistance exercise in individuals with and without cardiovascular disease. Circulation. 2000; 101(7): 828-33. https://doi.org/10.1161/01.CIR.101.7.828.

36. Kincaid B, Bossy-Wetzel E. Forever young: SIRT3 a shield against mitochondrial meltdown, aging, and neurodegeneration. Frontiers in aging neuroscience. 2013; 5. https://doi.org/10.3389/fnagi.2013.00048

37. Choo J, Burke LE, Hong KP. Improved quality of life with cardiac rehabilitation for post-myocardial infarction patients in Korea. European Journal of Cardiovascular Nursing. 2007; 6(3): 166-71. https://doi.org/10.1016/J.EJCNURSE.2006.07.004.

38. Siavoshi S, Roshandel M, Zareiyan A, Ettefagh L. The effect of cardiac rehabilitation care plan on the quality of life in patients undergoing coronary artery bypass graft surgery. Cardiovascular Nursing Journal. 2012; 1(2): 38-46.

39. Ma JK, Scribbans TD, Edgett BA, Boyd JC, Simpson $\mathrm{CA}$, Little JP, et al. Extremely low-volume, high-intensity interval training improves exercise capacity and increases mitochondrial protein content in human skeletal muscle. Open Journal of Molecular and Integrative Physiology. 2013; 3(04): 202. https://doi.org/10.4236/ojmip.2013.34027.

40. Marton O, Koltai E, Takeda M, Koch LG, Britton SL, Davies KJ, et al. Mitochondrial biogenesisassociated factors underlie the magnitude of response to aerobic endurance training in rats. Pflügers ArchivEuropean Journal of Physiology. 2015; 467(4): 779-88. https://doi.org/10.1007/s00424-014-1554-7.

41. Minamino T, Komuro I. Vascular cell senescence. Circulation research. 2007; 100(1): 15-26. https://doi.org/10.1161/01.RES.0000256837.40544.4a.

42. Ota H, Eto M, Kano MR, Kahyo T, Setou M, Ogawa $\mathrm{S}$, et al. Induction of endothelial nitric oxide synthase,
SIRT1, and catalase by statins inhibits endothelial senescence through the Akt pathway. Arteriosclerosis, thrombosis, and vascular biology. 2010; 30(11): 2205-11. https://doi.org/10.1161/ATVBAHA.110.210500.

43. Hou X, Xu S, Maitland-Toolan KA, Sato K, Jiang B, Ido $\mathrm{Y}$, et al. SIRT1 regulates hepatocyte lipid metabolism through activating AMP-activated protein kinase. Journal of Biological Chemistry. 2008; 283(29): 2001526. https://doi.org/10.1074/jbc.M802187200.

44. Chen D, Bruno J, Easlon E, Lin S-J, Cheng H-L, Alt $\mathrm{FW}$, et al. Tissue-specific regulation of SIRT1 by calorie restriction. Genes Dev. 2008; 22(13): 1753-7. https://doi.org/10.1101/gad.1650608.

45. Little JP, Safdar A, Wilkin GP, Tarnopolsky MA, Gibala MJ. A practical model of low-volume highintensity interval training induces mitochondrial biogenesis in human skeletal muscle: potential mechanisms. The Journal of physiology. 2010; 588(6): 1011-22. https://doi.org/10.1113/jphysiol.2009.181743.

46. Oliveira NR, Marques SO, Luciano TF, Pauli JR, Moura LP, Caperuto E, et al. Treadmill training increases SIRT-1 and PGC-1 $\alpha$ protein levels and AMPK phosphorylation in quadriceps of middle-aged rats in an intensity-dependent manner. Mediators of inflammation. 2014; 2014.

47. Casuso RA, Martínez-Amat A, Hita-Contreras F, Camiletti-Moirón D, Aranda P, Martínez-López E. Quercetin supplementation does not enhance cerebellar mitochondrial biogenesis and oxidative status in exercised rats. Nutrition Research. 2015; 35(7): 585-91. https://doi.org/10.1016/j.nutres.2015.05.007

48. Gurd BJ, Perry CG, Heigenhauser GJ, Spriet LL, Bonen A. High-intensity interval training increases SIRT1 activity in human skeletal muscle. Applied Physiology, Nutrition, and Metabolism. 2010; 35(3): 350-7. https://doi.org/10.1139/H10-030. 